share where both sharers are available together for the duration of the actual contract period. This applies to . . . junior medical staff". Since breadth of work experience is part of doctors' training, this contradicts other statements on equal training opportunities with full-time staff. There is also no commitment to job security for the remaining partner to complete the rotation if one partner passes MRCPsych and therefore leaves the scheme.

In training for General Practice, six sessions (one session $=0.5$ day) a week are the minimum allowed. The Royal College of Psychiatrists needs to consider whether 10 session job-shares are educationally sound. Trusts need to consider 12 session job-shares in place of 10 session fulltime posts and to review their policies on jobsharing for SHO rotations. Prospective employees need to be aware that local policies may differ and may have pitfalls. Although job-shares may be appropriate for some SHOs, positive action to create individual part-time training posts as an alternative to full-time training is also essential.

Claire Hilton, Senior Registrar, Kendal Day Unit, Bury New Road, Prestwich, Manchester M28 3BL

\section{Section 37 Hospital Order and rights of appeal}

Sir: We note the recent correspondence about Section 37 and rights of appeal (Psychiatric Bulletin. November 1996, 20, 965). C. Clark is correct in stating that patients detained under Section 37 cannot apply to a Mental Health Review Tribunal within the first six months. However, such patients do have another route by which their detention may be reviewed. As a Hospital Order is a form of sentence, patients can appeal against it (Criminal Appeal Act 1968 Section 50 (1)). A defendant may appeal from the Magistrates' Court to the Crown Court. To appeal he must give notice within 21 days after the conviction, to the Magistrates' Clerk and to the prosecution. A defendant may only appeal against sentence passed by the Crown Court either with leave of the Court of Appeal or the Crown Court Judge. The appeal procedure may be seen to be particularly important in the case of individuals placed under a Hospital Order from a Magistrates' Court when no conviction has been recorded, i.e. under the provisions of Section 37(3). Section 45 of the Mental Health Act specifically deals with this issue. It makes the point that any such patients will have the same right of appeal against the order as if it had been made on conviction.

Finally, the responsible medical officer has the discretion to discharge his patient from a hospital order at any time. This could be within the first six months, if appropriate.

These points may address the apparent anomaly between patients detained under Section 3 compared to those held under Section 37.

JONEs R. (1994) Mental Health Act Manual. London: Sweet \& Maxwell.

ELUNED DORKINS and CHRISTINE BROWN, Butler Clinic, Langdon Hospital, Exeter Road, Dawlish, Devon EX7 ONR

\section{Diazepam and detorification}

Sir: Duncan \& Taylor (Psychiatric Bulletin, 1996 , 20, 599-601) discuss chlormethiazole versus chlordiazepoxide in the treatment of the alcohol withdrawal syndrome. The authors do not discuss diazepam, which is safe in home and hospital settings and is avallable as tablet, syrup, rectal and intravenous preparations. Neither chlormethiazole nor chlordiazepoxide allow such flexibility of administration. Diazepam is the treatment of choice for convulsions while parenteral administration of the two drugs recommended is impossible or impracticable.

In the UK, detoxification usually comprises tapering doses of hypnosedatives over a period of 8-14 days. Local research on psychiatric wards suggests that doses prescribed are unrelated to alcohol consumption or past withdrawal symptoms, which risks under- and, more rarely, oversedation. An alternative approach, diazepam "loading dose therapy" has been shown to be effective in the management of moderate to severe alcohol withdrawal syndrome (Sellers et al, 1983) and to be more effective than conventional treatments in the management of delirium tremens (Wasilewski et al, 1996).

Using the traditional method, peak concentrations of long-acting drugs occur not during the first 72 hours, when most desirable, but towards the end of the detoxification period. Loading dose therapy utilises the pharmacokinetic properties of diazepam to minimise the duration of treatment. Diazepam, $20 \mathrm{mg}$ one to two hourly, is titrated against symptoms and signs, measured using the Clinical Institute Withdrawal Assessment scale (CIWA-Ar) (Sullivan et al, 1989). When scores fall below 11, usually within 24 hours, no further drug treatment is required.

This technique appears to be as effective, quicker and safer than standard treatment and is being introduced into the Cardiff service. We would be interested to hear from others who are using this method of treatment. 